\title{
Commentary
}

\section{Is Bleomycin a worthy alternative?}

\author{
Jyotsna Murthy \\ Department of Plastic Surgery, Sri Ramachandra Medical College and RI, Chennai, India.
}

Address for correspondence: Dr. Jyotsna Murthy, Department of Plastic Surgery, Sri Ramachandra Medical College and RI Chennai, India. E-mail: murthyjyotsna@gmail.com

B leomycin is an antibiotic discovered in 1966 and used as anti-cancer drug. It has also been used as sclerosant for lymphatic malformation with good results and minimum side effect. Like any sclerosant agent, bleomycin is popular for the treatment of lymphatic malformation with publication as recent as in January 2011..$^{[1]}$ Unlike surgery, sclerotherapy is better specially for avoiding injury to important nerves or structures in vicinity of lesions. ${ }^{[2]}$ Acute pulmonary complication is a potential threat with bleomycin which need to be diagnosed early and treated. ${ }^{[4]}$

This study has shown the positive outcome, it does not scientifically draw conclusion for the following reasons.

\section{APPROPRIATE DIAGNOSIS}

In 1996, the International Society of the Study of Vascular Anomalies met in Rome issued guide for nomenclatures laying foundation for improve management. ${ }^{[5]}$ Often it has been printed 'Wrong Diagnosis, Wrong Treatments'. The group has suggested two basic classifications of vascular anomalies: haemangiomas and vascular malformation. Lymphatic malformation belongs to vascular malformation and further classified as micro-cystic or macro-cystic. The lesions with more than $1 \mathrm{~cm}$ cavities are classified as macrocystic lesions. The diagnosis of lesions in this article is haemangiomas and lymphangiomas which are not comparable. Lymphatic malformations have not been subclassified into micro/macro-cystic lesions because macro-cystic lesion will respond to sclerotherapy unlike micro-cystic one. The lack of clarity of diagnosis prevents any sound conclusion.

\begin{tabular}{|l|l|}
\hline \multicolumn{2}{|c|}{ Access this article online } \\
\hline Quick Response Code: & Website: \\
\hline & www.ijps.org \\
\cline { 2 - 2 } & Dol: \\
\hline
\end{tabular}

Indian Journal of Plastic Surgery January-April 2011 Vol 44 Issue 1

\section{TREATMENT OPTION}

Bleomycin is an antibiotic with toxic cellular effect for which it has been used as an anti-cancer drug. It is also used for collapsing cavities specially following malignant effusion. Bleomycin has shown to be less effective than tetracyclin injections..$^{[5]}$ The tretracyclin injections are not easily available. However, its analogue doxycycline and monocyclin are available, and show similar results. Proper dose and concentration are paramount for the effectiveness of any drug. The concentration of bleomycin is $1 \mathrm{U}=1 \mathrm{mg}$ and concentration of $1 \mathrm{U} / \mathrm{ml}$ for injection is essential to get $60 \%$ of successful results. Authors' claim to have the same effect with lesser concentration without any scientific study is superfluous. Although injections of bleomycin are less painful compare to other sclerosant, it is a costly drug (approximate costs \$350/15 units).

In view of the above lacunae in the study, it is not appropriate to draw any conclusion from this study but it only presents the anecdotal experience of author with bleomycin. A better diagnostic criteria and study design would have really been invaluable.

\section{REFERENCES}

1. Yang $\mathrm{Y}$, Sun $\mathrm{M}, \mathrm{Ma} \mathrm{Q}$, Cheng $\mathrm{X}$, Ao J, Tian L, et al. Bleomycin A5 sclerotherapy for cervicofacial lymphatic malformations. J Vasc Surg 2011;53:150-5.

2. Karavelioğlu A, Temuçin CM, Tanyel FC, Ciftci AO, Senocak ME, Karnak I. Sclerotherapy with bleomycin does not adversely affect facial nerve function in children with cervicofacial cystic lymphatic malformation. J Pediatr Surg 2010;45:1627-32.

3. Atwa K, Abuhasna S, Shihab Z, Hashaykeh N, Hasan R. Acute pulmonary toxicity following intralesional administration of bleomycin for a lymphovenous malformation. Pediatr Pulmonol 2010;45: 192-6.

4. Mulliken JB, Fischman SJ, Burrow PE. Vascular Anomalies. Curr Prob Surg 2000;37:517.

5. Vargas FS, Wang NS, Lee HM, Gruer SE, Sassoon CS, Light RW. Effectiveness of bleomycin in comparison to tetracycline as pleural sclerosing agent in rabbits. Chest 1993;104:1582-4. 